\title{
Lake Area Analysis Using Exponential Smoothing Model and Long Time-Series Landsat Images in Wuhan, China
}

\author{
Gonghao Duan ${ }^{1, *}$ (D) and Ruiqing Niu ${ }^{2}$ \\ 1 Faculty of Information Engineering, China University of Geosciences, Wuhan 430074, China \\ 2 College of Geophysics and Geomatics, China University of Geosciences, Wuhan 430074, China; \\ rqniu@163.com \\ * Correspondence: vipdgh@163.com
}

Received: 14 November 2017; Accepted: 8 January 2018; Published: 9 January 2018

\begin{abstract}
The loss of lake area significantly influences the climate change in a region, and this loss represents a serious and unavoidable challenge to maintaining ecological sustainability under the circumstances of lakes that are being filled. Therefore, mapping and forecasting changes in the lake is critical for protecting the environment and mitigating ecological problems in the urban district. We created an accessible map displaying area changes for 82 lakes in the Wuhan city using remote sensing data in conjunction with visual interpretation by combining field data with Landsat 2/5/7/8 Thematic Mapper (TM) time-series images for the period 1987-2013. In addition, we applied a quadratic exponential smoothing model to forecast lake area changes in Wuhan city. The map provides, for the first time, estimates of lake development in Wuhan using data required for local-scale studies. The model predicted a lake area reduction of $18.494 \mathrm{~km}^{2}$ in 2015 . The average error reached 0.23 with a correlation coefficient of 0.98 , indicating that the model is reliable. The paper provided a numerical analysis and forecasting method to provide a better understanding of lake area changes. The modeling and mapping results can help assess aquatic habitat suitability and property planning for Wuhan lakes.
\end{abstract}

Keywords: lake; forecasting; mapping; quadratic exponential

\section{Introduction}

With the development of remote sensing technology, increasingly large data sets of imagery have been used for water resource assessment [1,2]. The Hubei Province is known as "the province of a thousand lakes" in China, as there are more than 80 shallow lakes densely distributed throughout the Wuhan development area alone. The loss of lakes significantly influences the level of environmental pollution as well as climate change in a region, and this loss represents a serious and unavoidable challenge to maintaining ecological sustainability under the circumstances of lakes that are being filled. Therefore, mapping changes in lake areas is critical for protecting the environment and mitigating ecological problems in the Wuhan urban area.

Several mapping water studies have been conducted for different research fields. They noted the importance of wetlands for urban landscape planning and delineated the relationship between human health and urban wetland environmental ecosystems [3,4]. Researchers quantified the changes in both lake areas and boundaries from multiple sets of remote sensing images [5,6]. Satellite remote sensing plays a significant role in water resource surveying, hydrological monitoring, wetland protection, and geological disaster warning systems because of the periodic repetition of data and the ability to cover a large area [7-10]. Experts obtained the modified normalized difference water index (MNDWI) by analyzing the differences in the amounts of radiation received from water bodies 
and non-water features [11]. Some experts made a comparative study of automated water classification methods [12] and used moderate-resolution sensor imagery, such as that acquired from the Landsat Thematic Mapper (TM) and Moderate Resolution Imaging Spectroradiometer (MODIS) sensors, to obtain the distributions of desired features among various study areas [13-15]. Many investigations primarily utilized remote sensing images from the last 10 years to explore changes in lake areas or other features to study developmental changing trends resulting from human interaction with the environment [16-22]. The lakes in the Wuhan urban district are taken as research subjects herein to apply a novel approach [23-25] to map lake changes over a nearly 30-year period. We utilize the MNDWI and the relationships among various remote sensing bands to extract the spatial information of lake surfaces between 1987 and 2013. Furthermore, we provide a valid exponential model to forecast future changes. The set of measures used herein includes the degree of model fit, the robustness of the model, and the prediction skill [26-29]. Finally, we map the changes in lake area throughout the Wuhan urban development district (1987-2013), the results of which are readily explainable and may possess practical applications.

\section{Study Area}

The city of Wuhan is located to the east of Jianghan Plain and is situated in the middle of China with a total area of $8494.41 \mathrm{~km}^{2}$. The city is divided into three parts by two major rivers that cut through the city centre: the Yangtze River, which is the third largest river in the world and the Hanjiang River (the Yangtze River's largest tributary). The collective water surface of the two rivers, covering up to $2217.6 \mathrm{~km}^{2}$, accounts for nearly a quarter of the urban distinct, which is the highest among all of China's major cities (Figure 1a).

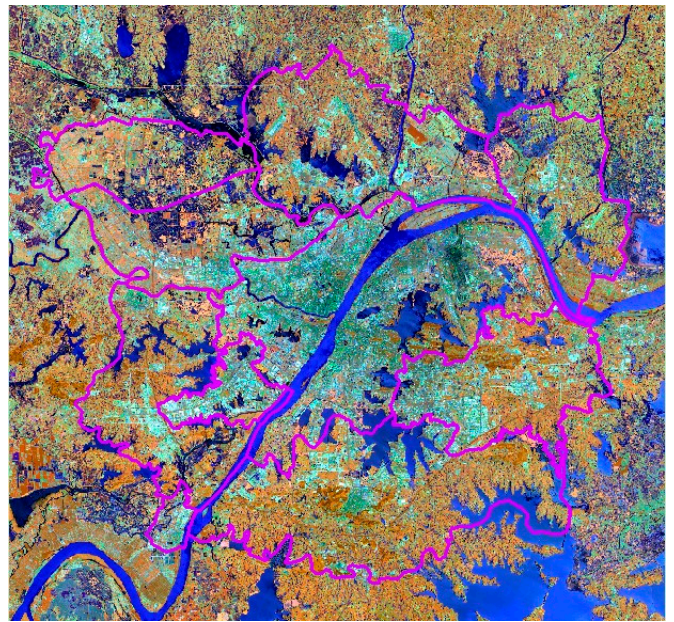

(a)

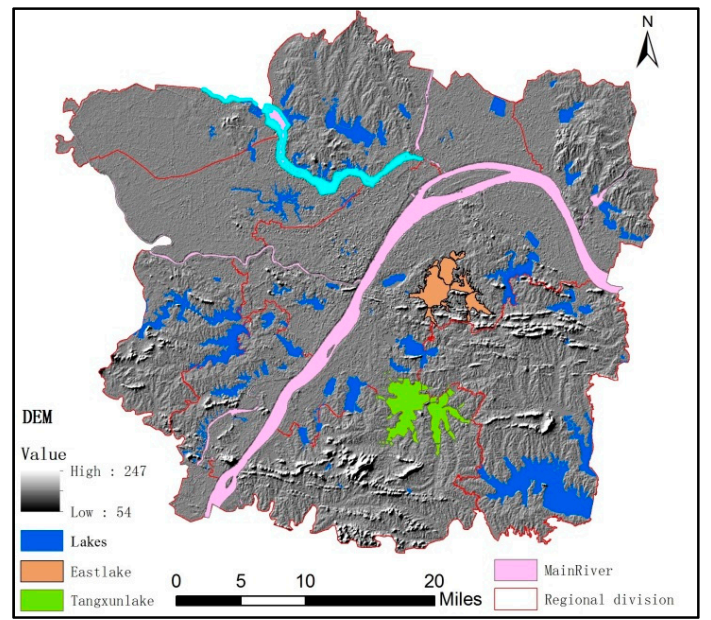

(b)

Figure 1. (a) represents the newest Wuhan urban boundary shape file that we employ to cover the Landsat 8 remote sensing image (2013); (b) shows a relatively scattered distribution of lakes, which are mainly concentrated within central and southern Wuhan. The lakes are more likely to appear in low-lying areas with higher elevations, and many small lakes are developed around the main river. The two largest urban lakes (East Lake and Tangxun Lake) are located in the middle-west section of the study area. This lake distribution shows that there are abundant water resources in the urban area.

As of 2015, there were approximately 166 lakes in Wuhan, which is known as the "city of the hundred lakes". The lake surface area was $803.17 \mathrm{~km}^{2}$ at normal water level. Tangxun Lake $\left(47.6 \mathrm{~km}^{2}\right)$ is the largest city-lake in China at present [30]. Many large lakes are situated on either side of the two main rivers, forming a network of lakes (Figure 1b). Our research team conducted a thorough study of the 82 main lakes in the Wuhan urban area by means of follow-up methods. 
In our research, we focus on annual changes in the body of the main lakes (1987-2013). The information of the lake boundaries is extracted from remote sensing data, including the characteristics of the electromagnetic radiation from earth objects. As a result, we provide a priori knowledge for the protection of water resource environments in Wuhan. In addition to techniques for the extraction of lake areas using, for example, the MNDWI, we also conducted field trips to every lake. Figure 2 shows the field conditions of the South Prince Lake. More details will be discussed in the Results and Discussion sections.

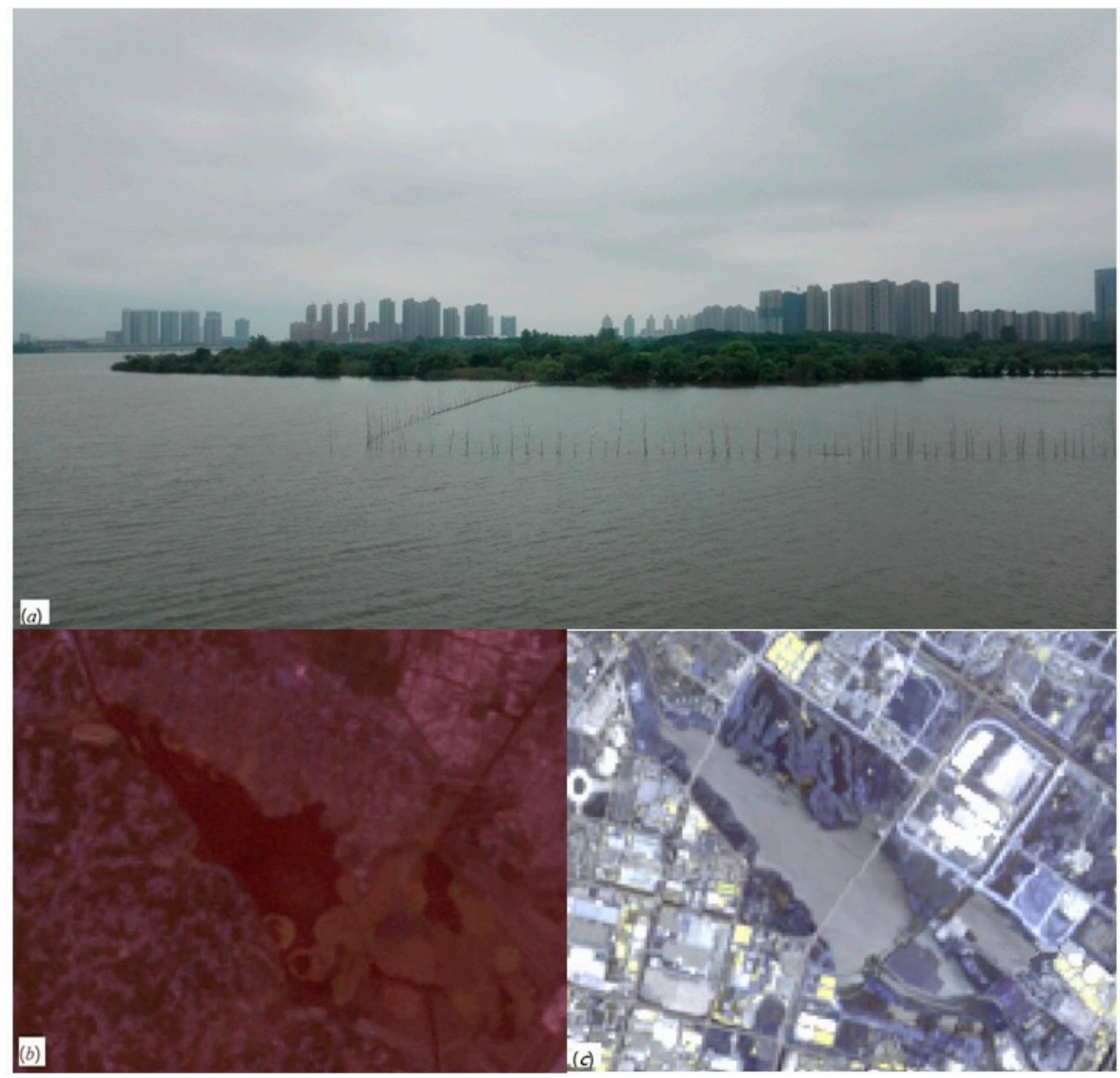

Figure 2. Field photographs depicting South Prince Lake in 2015 (a); Residential buildings and communities are observed near the lake. The area was well retrieved in Landsat 8 imagery in 2013 (b) and in Landsat 5 imagery in 2001 (c); The water area in 2013 (b) was slightly decreased due to real estate projects in the southeastern corner, and some parts were filled for industrial use.

\section{Materials and Methods}

Lakes area change were a comprehensive result of many external factors, so our research did not focus on any external factors affecting lake increase or loss, such as climate changes, and only addresses the general lake changes in Wuhan. We organized the images taken during the period from 1987 to 2013 in consideration of the acquisition time, coverage, cloudage, and whether resolved stripes were available. Then, we overlay the images over the Wuhan urban area so that the selected data can fully cover the research area. We choose images such that their total cloudage was less than $10 \%$. This step is important because excessive cloud cover can obscure water bodies and induce difficulties in subsequent extraction tasks. 
Based on the above considerations, we choose over 10 periods of images as a data set spanning from 1987 to 2013 to study variations in the major lakes of the Wuhan urban area. The remote sensing images used in this paper were all acquired from the Landsat satellites, and the data were obtained from either a cloud-based database of geographic information from the Chinese Academy of Sciences or the United States Geological Survey (USGS) website. Our research takes advantage of the above data to study the linear and polygonal layers of lakes primarily through a water extraction method in addition to visual interpretation within ArcGIS. The main image data are presented in Table 1, and a sample well-processed image is shown in Figure 3.

Table 1. Image data set.

\begin{tabular}{|c|c|c|c|c|c|}
\hline Satellite & Sensor & Resolution (m) & Data Identification & Date & Cloudage $(\%)$ \\
\hline Landsat 4 & TM & $30 \mathrm{~m}$ & LT41230391989042XXX02 & $1989 / 02 / 11$ & None \\
\hline \multirow{5}{*}{ Landsat 5} & \multirow{5}{*}{ TM } & \multirow{5}{*}{$30 \mathrm{~m}$} & LT51230391987253BJC00 & $1987 / 9 / 10$ & $4.7 \%$ \\
\hline & & & LT51230391994272BJC00 & $1994 / 9 / 29$ & None \\
\hline & & & LT51230392001259BJC00 & $2001 / 9 / 16$ & $6.7 \%$ \\
\hline & & & LT51230392005254BJC00 & $2005 / 9 / 11$ & $9 \%$ \\
\hline & & & LT51230392009249BJC00 & $2009 / 9 / 6$ & None \\
\hline \multirow{3}{*}{ Landsat 7} & \multirow{3}{*}{ ETM+ } & \multirow{3}{*}{$30 / 15 \mathrm{~m}$} & LE71230392003273EDC01 & $2003 / 9 / 30$ & $6 \%$ \\
\hline & & & LE71230392007332EDC00 & $2007 / 11 / 28$ & None \\
\hline & & & LE71230392011343EDC00 & 2011/12/9 & None \\
\hline Landsat 8 & OLI & $30 / 15 \mathrm{~m}$ & LC81230392013164 LGN00 & $2013 / 6 / 13$ & None \\
\hline
\end{tabular}

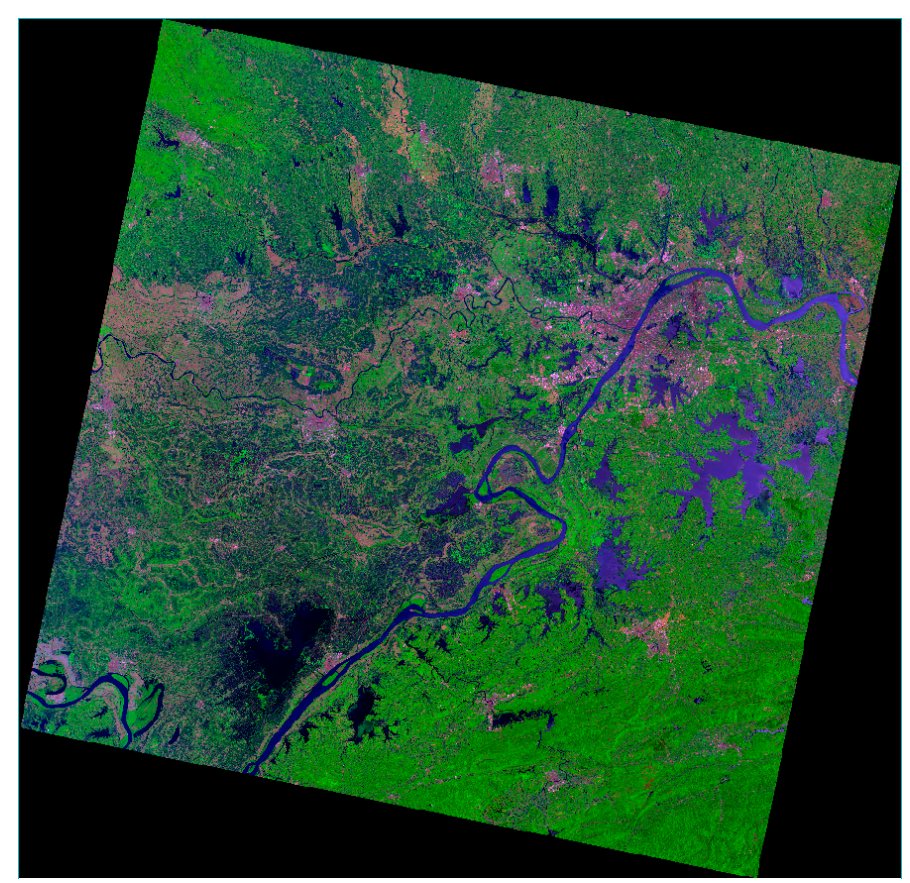

Figure 3. Operational Land Imager (OLI) remote sensing image (Wuhan urban area, Landsat 8, 13 June 2013) that was processed using radiation correction, atmospheric calibration, area shape cutting and strip repair work.

\subsection{Water Extraction}

The images used herein consist of two types of data organisation schemes. The range of grey values of the TM and Enhanced TM Plus (ETM+) sensors is between 0 and 255 (pre-2013) and the grey values of the Landsat 8 Operational Land Imager (OLI) sensor range from 0 to 65,535 (post-2013). 
With the same image resolution, the information in the Landsat- 8 imagery is undoubtedly greater [31]. Therefore, we adopted two different methods for the water extraction under two separate conditions. Image classification and feature extraction processes are complex and may be affected by many factors [32]. The brightness value of water is different from those of shoals and shaded relief but is similar to those of settlements or woodlands in bands 2 and 3 of TM and ETM+ images, and it is less than those of other surface features in bands 4 and 5. With these reflection characteristics, we can effectively distinguish between water and other surface features by choosing a specific band combination. In addition, we can exclude the effects of interference from shaded relief and snow by setting a threshold. In this paper, we select bands 3, 4, 5 and 6 to perform the band operations because there is a broad range of image brightness values in OLI data. Moreover, the ratios of the brightness values in bands 3 and 4 and in bands 5 and 6 , which effectively represent water bodies, will be amplified. The model we use in Landsat 8 can be written as follows:

$$
(\mathrm{OLI} 3+\mathrm{OLI} 4) /(\mathrm{OLI} 5+\mathrm{OLI} 6)>1,
$$

Normally, water bodies are characterized by (TM2 + TM3) > (TM4 + TM5) [33]. We calculate the brightness of an image pixel by placing a strong reflection band in the numerator and a weak reflection band in the denominator, following which their contrast will be further expanded. Accordingly, the brightness of the studied feature in the resulting image will be the maximum and the other features will be correspondingly suppressed, which will make the water surface easily differentiable from background objects. The MNDWI [11] that we employ for the TM and ETM+ images (pre-2013) can be written as follows:

$$
(\mathrm{p}(\text { Green })-\mathrm{p}(\mathrm{MIR})) /(\mathrm{p}(\text { Green })+\mathrm{p}(\mathrm{MIR}))>0.44,
$$

\subsection{The Quadratic Exponential Smoothing Model}

The extraction of the water surface may reflect changes in the lake area at a given time, but future changes in the lake area are often required for more thoughtful measures. An exponential smoothing model, which is a special type of weighted average model, is sensitive to historical data that is close to the forecasting period, and the weight of the model declines with increasing time [34,35]. The exponential smoothing model requires fewer training data and less modeling time, lake area generally has a decreasing tendency and historical relevance year by year, so this model is therefore more suitable for evaluating complex variations in lake surface areas than other models. In addition, when the trend of the data is either rising or falling, the quadratic exponential smoothing method will be more effective because the single exponential method may output large forecast deviations [36]. The quadratic exponential smoothing method applies exponential smoothing based on the single exponential smoothing model by simultaneously considering the overall trend of the curve [37]. In most cases, we only require three sets of input training data and a parameter value that can be utilized to establish the forecast model. As lake areas are essentially decreasing on an annual basis, this algorithm is well adapted for predicting lake areas.

The linear quadratic exponential smoothing method is described using the following equation:

$$
\begin{aligned}
& S_{t}^{(1)}=a Y_{t-1}+(1-a) S_{t-1}{ }^{(1)}, \\
& S_{t}{ }^{(2)}=a S_{t}{ }^{(1)}+(1-a) S_{t-1}{ }^{(2)},
\end{aligned}
$$

In this paper, $S_{t}$ and $S_{t-1}$ represent the smoothing values for the lake areas at times $t$ and $t-1$, respectively, and $a$ is the smoothing coefficient, namely, the damping coefficient [38]. $Y_{t-1}$ is the actual lake area at $t-1$. The values of $S_{t}^{(1)}$ and $S_{t}{ }^{(2)}$ are known, and the quadratic exponential smoothing model can be written as follows:

$$
F_{t+T}=d_{t}+b_{t} T,
$$




$$
\begin{gathered}
d_{t}=2 S_{t}^{(1)}-S_{t}^{(2)}, \\
b_{t}=a\left(S_{t}^{(1)}-S_{t}^{(2)}\right) /(1-a),
\end{gathered}
$$

$T$ denotes the predictive periods, $F_{t+T}$ represents the predicted value of the lake area at the time $t+T$, and both $d_{t}$ and $b_{t}$ are parameters of the data at the time $T$. It is not difficult to discern from Formulaes (3)-(7) that the value of the smoothing parameter $a$ plays a crucial role, as it reflects the approximation of the predicted value with respect to the current data value [39]. In practical applications, the smoothing parameter is a constant between 0 and 1 . When $a$ approaches 1 , the predicted values will be closer to the current value and far from the smoothness value of the historical data, and the slope of the preceding curve will be changing faster prior to becoming steep. When $a$ approaches 0 , the predicted value will be closer to the smoothness value of the historical data, which means the curve will be smoother than before (Figure 4). In previous studies, the smoothing coefficient was generally based on the principle of the minimum mean square deviation, and experienced methods were often utilised to confirm the values of the smoothness parameters [40]. Our research considers the characteristics of lake areas affected by annual variations, and we have determined that 0.9 is the optimal smoothness coefficient after conducting many tests.

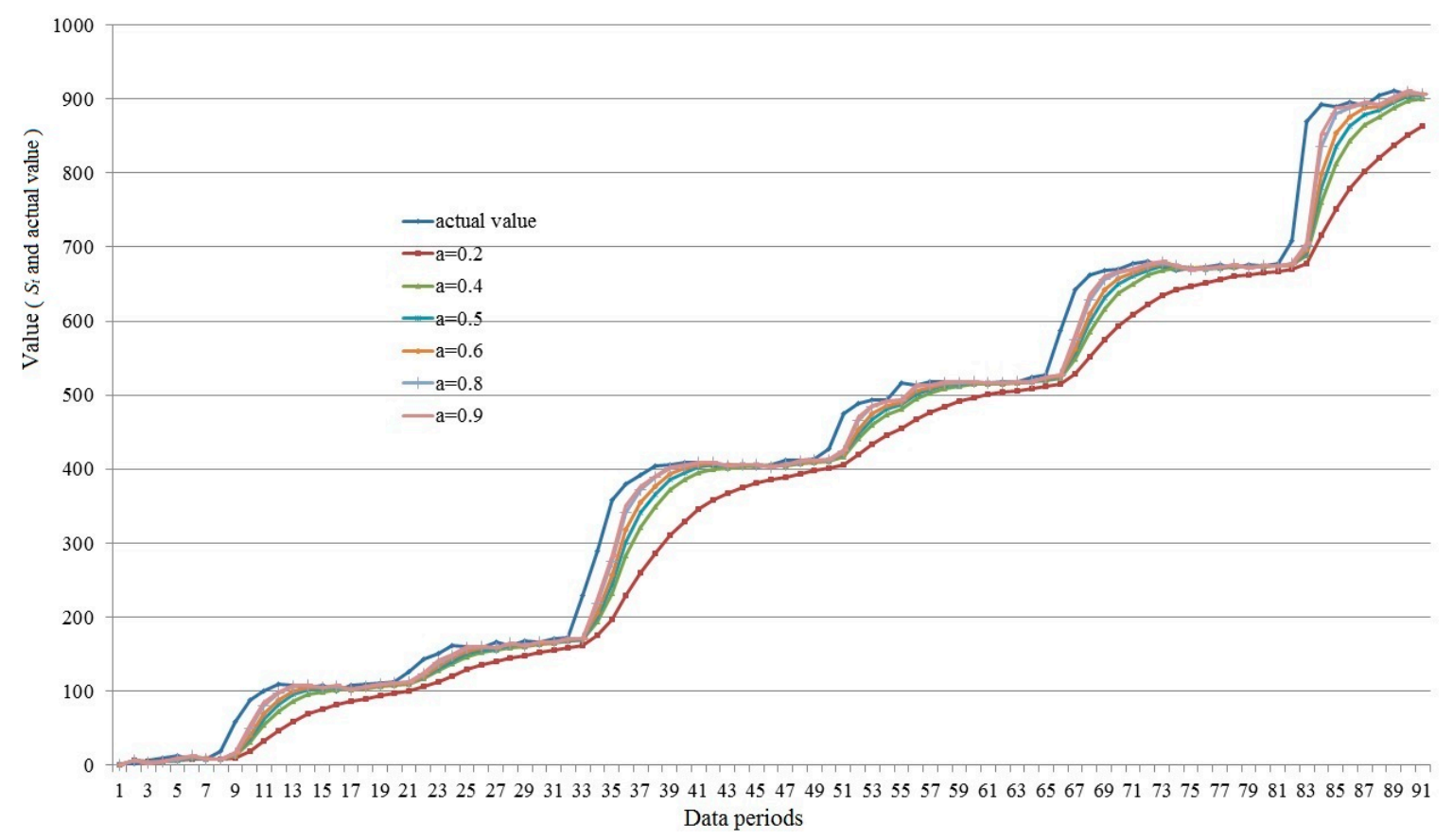

Figure 4. Variation of $S_{t}$ with smoothing parameter. We use an incremental sequence as an example, and the predicted values $\left(S_{t}\right)$ will be closer to the current value and far from the smoothness value of the historical data, the slope of the preceding curve will be changing faster prior to becoming steep.

In addition, some experts used the mean absolute error $(M A E)$ and correlation coefficient $(R)$ to represent the prediction accuracy of the quadratic exponential smoothing model [41], the formulae for which are given as follows:

$$
\begin{gathered}
M A E=\frac{1}{n} \sum|Y(t)-\hat{Y}(t)| \\
R=\frac{\sum\left[\left(A_{i}-\bar{A}\right)\left(B_{i}-\bar{B}\right)\right]}{\sqrt{\sum\left(A_{i}-\bar{A}\right)^{2}} \times \sqrt{\sum\left(B_{i}-\bar{B}\right)^{2}}}
\end{gathered}
$$


$Y(t)$ is the actual value while the other variable represents the predicted value of the model, and $n$ is the total number of data in Formula (8). In Formula (9), $A_{i}$ and $B_{i}$ represent the actual value and the predicted value of the model, the other variable represents the mean of the two values. Smaller $M A E$ values indicate smaller model errors, while larger $R$ values represent higher correlations between the fitted data and actual values, thereby suggesting that the model has a better forecasting ability. Considering the effect of overfitting in forecasting models for long period cases, our research only predicted lake area in 2015 for a better accuracy and understanding.

\subsection{Lake Area Change Index}

The lake evolutionary history includes body changes, spatial transformations, and quality changes. As areal deformations are first reflected within the imagery, we can initially understand the overall developmental trends of the lakes. The changes in the lake areas and their rates of change may directly reflect the evolution of the ecological environment. Therefore, we took the following equation to describe the extent of the variability in the water bodies:

$$
\begin{gathered}
L_{1}=U_{b}-U_{a}, \\
L_{2}=\left(U_{b}-U_{a}\right) / T,
\end{gathered}
$$

$L_{1}$ represents the total range of the variability, $L_{2}$ denotes the range of annual variations of the lakes, $U_{a}$ and $U_{b}$ represent the lake areas at the beginning and end of a study period, and $T$ is the number of years between the starting and ending times. As a result, the area of a lake will increase when $L_{1}>0$ and decrease when $L_{2}<0$.

However, for equivalent amplitudes of the total variation or annual variation amplitudes, the actual situations reflected within many periods will be different. To obtain a better description of the relative variations among different periods, we use a lake change intensity index to analyse the relative intensity of area changes. The lake change intensity index can be written as follows:

$$
C=100 \times \Delta A_{b a} /\left(A_{a} \times \Delta t\right),
$$

$C$ is the area intensity index of the lake evolution, $\Delta A_{b a}$ represents the areal changes within the period from $a$ to $b$, and $A_{a}$ is the total area of the lakes during the year $a$.

\section{Results and Discussion}

\subsection{Lake Area Change Analysis and Forecasting}

First, we transform the projection according to the Beijing 54 coordinate system for the original remote sensing imagery of the study area and then match the image with a standard geologic map. Subsequently, we use the Wuhan urban development area as a mask to cut out the Landsat 8 remote sensing image. Second, we utilize the MNDWI and the relationships among the sensor bands to distinguish the water bodies from other surface features. We obtained the lake shape data for the study region following binarization and vectorization. Then, after visual interpretation, the spatial location and size of each lake were confirmed, after which we added the generated vector layer of the lake areas as another attribute.

Finally, the lakes layer was converted into a raster layer to detect changes. We use the spatial and statistical analysis functions of GIS to calculate the areas of the lakes. The results are shown in the charts of Figure 5.

To better study the annual variations in the lake areas and to analyse the source of the variations over the two-year periods, we use Formulas (10) and (11) to acquire the total range of variability and the range of annual variations, respectively, for the changes among all of the lakes. The results are shown in Figure 6. 


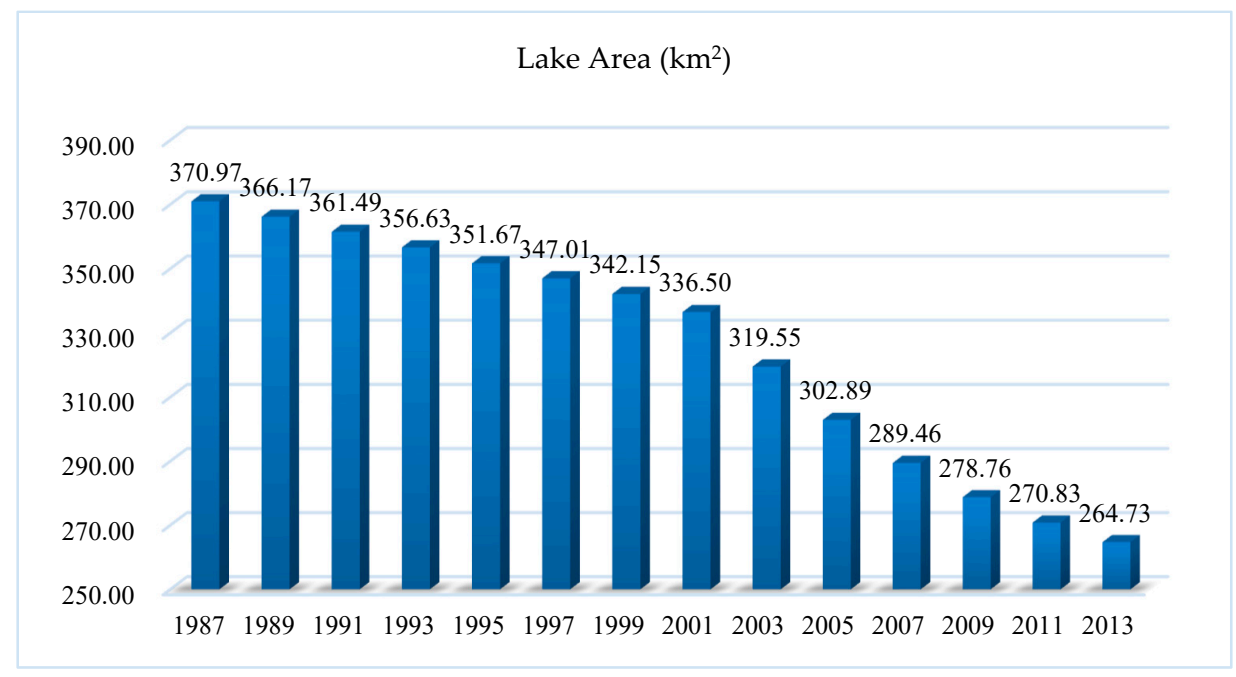

Figure 5. Total area of all of the lakes in the Wuhan urban area (1987-2013). The lake area statistics from every two years are compared, revealing an overall annually decreasing trend. With a decline in the total area from $370.97 \mathrm{~km}^{2}$ in 1987 to $264.73 \mathrm{~km}^{2}$ in 2013, a total decrease of $106.24 \mathrm{~km}^{2}$ occurred over a period of twenty-six years.

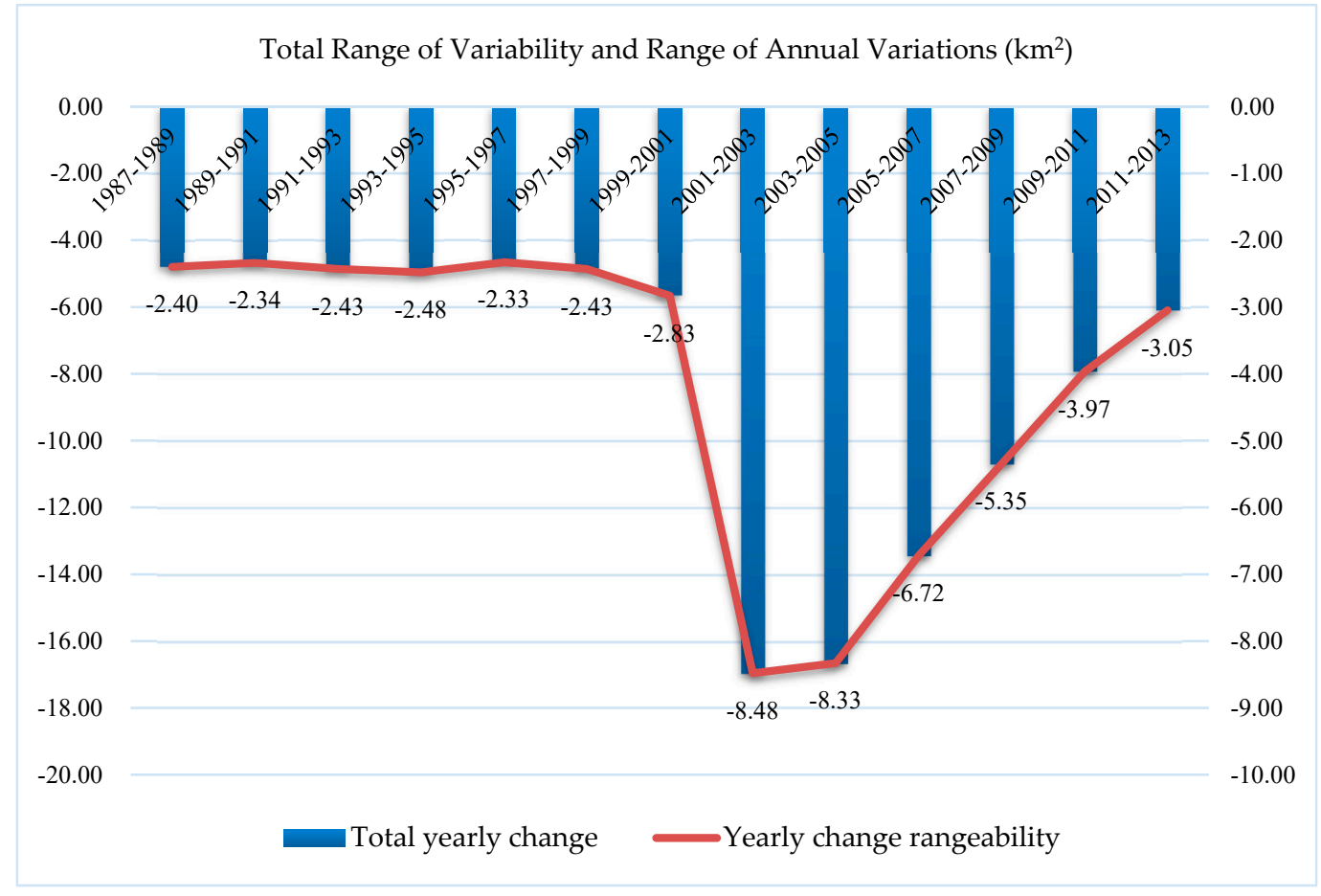

Figure 6. Total variations in the lake areas in the Wuhan urban area (1987-2013).

The data for the period between 1987 and 2001 show that the average annual rate of decrease of the lakes in the urban development areas was approximately $2.33-2.83 \mathrm{~km}^{2}$ per year, which means that lake conservation efforts were effective during that time. However, from 2001 to 2005, the annual rate of decrease rapidly increased to 8.33 and $8.48 \mathrm{~km}^{2}$ per year, wherein more lakes needed to be restored. Furthermore, between 2005 and 2013, the entire average lake area began to decrease annually. As a result, the variations in the total lake area went through three stages: during 1987-2001, the water area shrank slowly and in a stable manner, and the lakes of Wuhan city were healthy and in good 
condition; during 2001-2005, the lake surface area diminished at a relatively rapid rate because increasing numbers of residential buildings and community projects were constructed near the lakes, following which the ecological environments of the lakes further deteriorated; during 2005-2013, people began to realize the importance of the lakes to the urban ecology, and the reduction in the lake areas became less gradual. According to two main indictors shown in Figure 6, we then calculated the lake change intensity index for Wuhan (Figure 7).

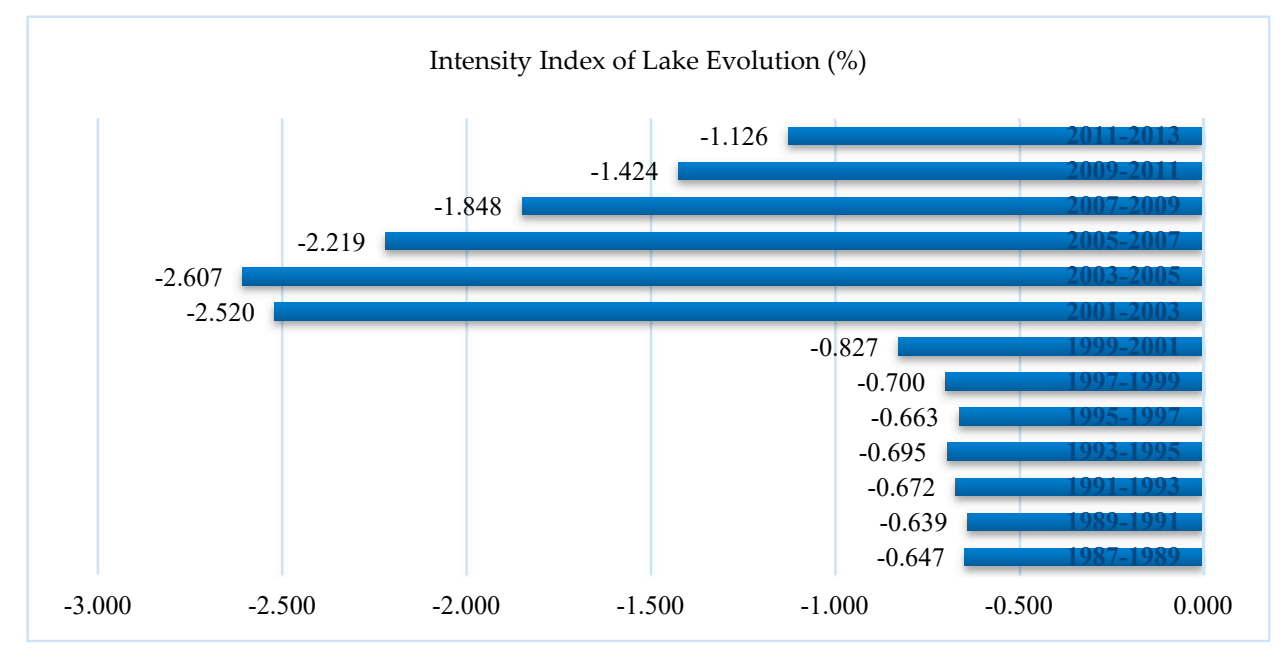

Figure 7. Total changes in the lake areas in the Wuhan urban area (1987-2013).

The change intensity index of the lakes can reveal a clearer, more realistic meaning than the actual change values for the lake areas in a time interval. In Figure 7, the lake change intensity shows that the urban lake change intensity index maintained values less than -0.827 from 1987 to 2001, which, compared with the whole observational period, is a relatively weak magnitude of variation. Between 2001 and 2007, the intensity index increased sharply to values ranging from -2.607 to -2.219 , which are 3-4 times those between 1987 and 2001. The intensity index peaked at -2.607 in 2003-2005. The variability of the lake areas was dramatic during the next 7 years. Between 2007 and 2013, the intensity index dropped to values between -1.848 and -1.126 in 2011-2013, proving that the variation amplitude was clear and that the changes in the lake areas were going to slow down year by year.

We studied the annual variation in the area of South Prince Lake as an example for the period between 1987 and 2013. South Prince Lake is located in the middle-west of the Wuhan area (Figure 8) and is adjacent to the Yangtze River. According to the water surface extracted from the remote sensing imagery, we can see the evolution process as presented in Figures 9 and 10.

As shown in Figure 10, the data for each time period were negative among the three indicators, indicating that the overall ecological environment of South Prince Lake was in a state of reduction. The amplitude of variation and the yearly rangeability show that the lake was in an accelerated stage of atrophy between 1987 and 2005 and in a deceleration phase between 2005 and 2013. During the two periods of 1987-1994 and 2011-2013, the yearly rangeability reached $-0.46 \mathrm{~km}^{2}$ and $-0.31 \mathrm{~km}^{2}$, which does not constitute a large difference. This was perhaps due to slow urban development in 1987-1994, during which time human engineering activity was not substantial. In addition, additional laws and regulations for the preservation of the lake were published in 2011-2013, during which time urban construction was in a phase of rapid development, and thus, the rate of reduction of the lake was more stable. In addition, the intensity index can reflect the influences of human engineering activities on lakes. We found that the peak of -3.883 in 2003-2005 belongs to a burgeoning period of engineering activity in Wuhan. Meanwhile, the slow atrophy phase (2005-2013) exhibited a diminished rate of areal reduction with two brief falls in the lake area, which may have been related to the improved ecological environment. 


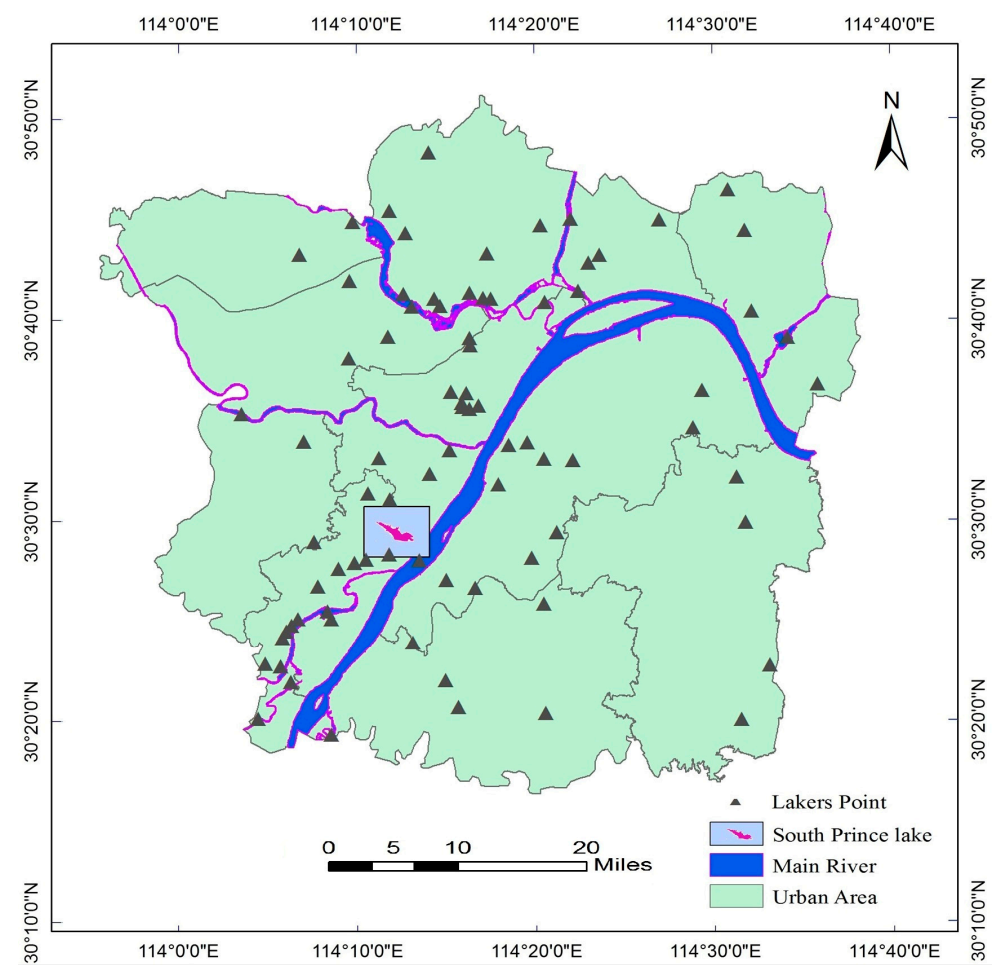

Figure 8. Distribution of selected large, key lakes throughout Wuhan. In 2015, We also conducted field trips to every lake to improve the results of comparisons between the image interpretations and the actual lake changes.
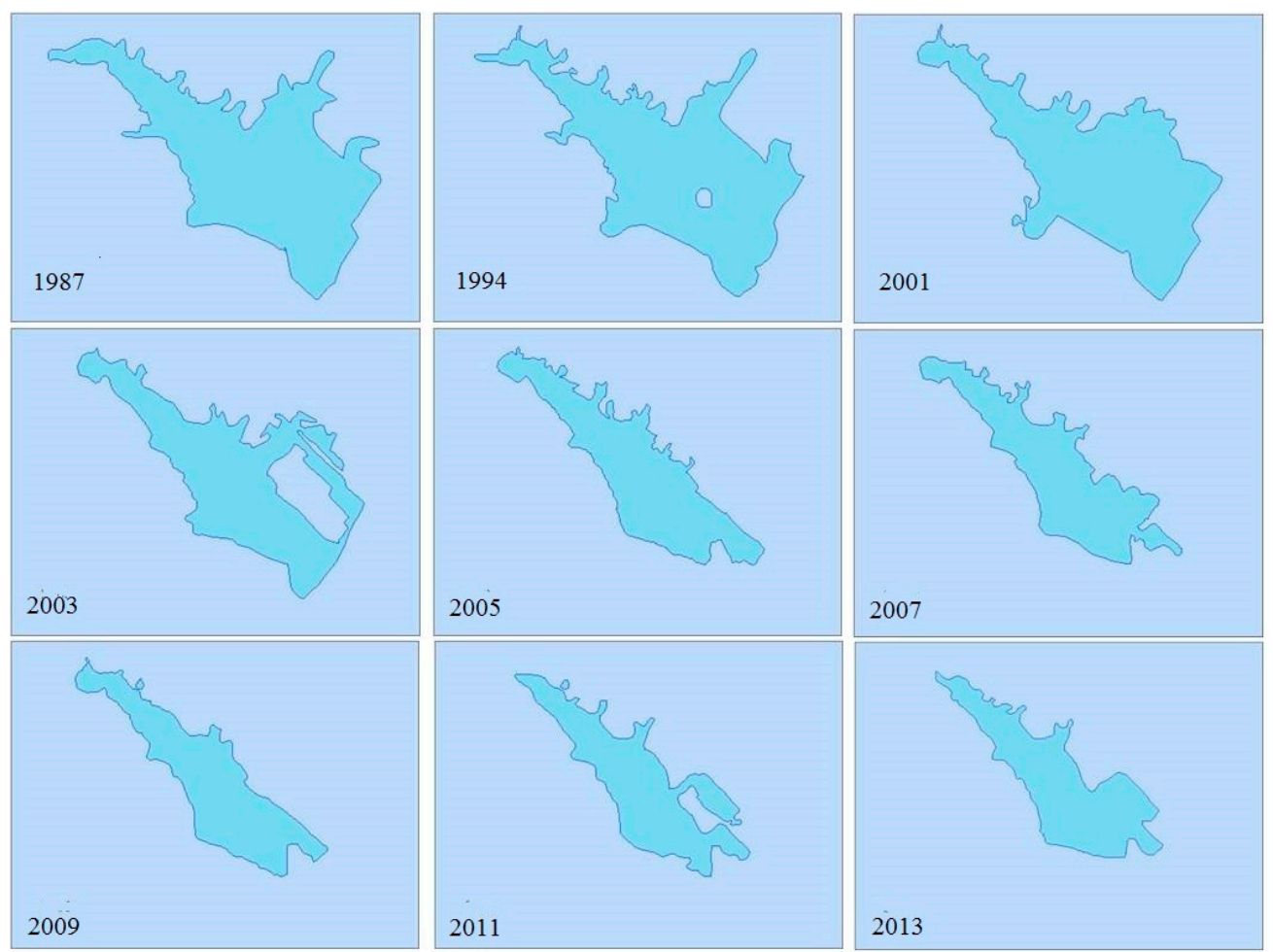

Figure 9. Evident areal changes of South Prince Lake (1987-2013). The area at the southeast corner of the lake was clearly reduced, and field observations revealed that industrial construction had filled the lake in 2013. 


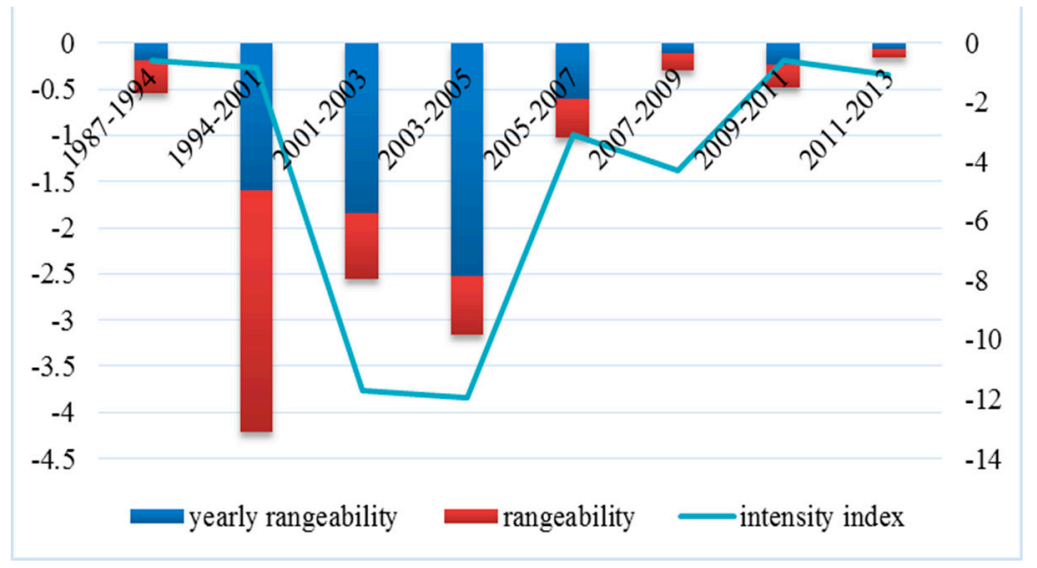

Figure 10. Change indicators for South Prince Lake (1987-2013).

Existing images have been able to fully describe the changes in the lakes, but we require the support of data models to forecast future trends in their areal evolution. As mentioned in the previous chapter, our study applies a quadratic exponential smoothing model to predict the changes over the next 2 years in the Wuhan urban area. After repeated tests, we found that the average error will be minimized when the smoothing parameter is set to 0.9. This is because both the water environment and human factors, which are greatly responsible for changes in the lakes, will continue to affect the lake areas, and the current rate of decrease in the lake area is closely associated with the ecological environment of the previous year. Therefore, the smoothing parameter will undoubtedly be relatively large. Taking Sand Lake, South Prince Lake, and South Lake as examples, the modeling results and the actual values are compared in Figure 11.
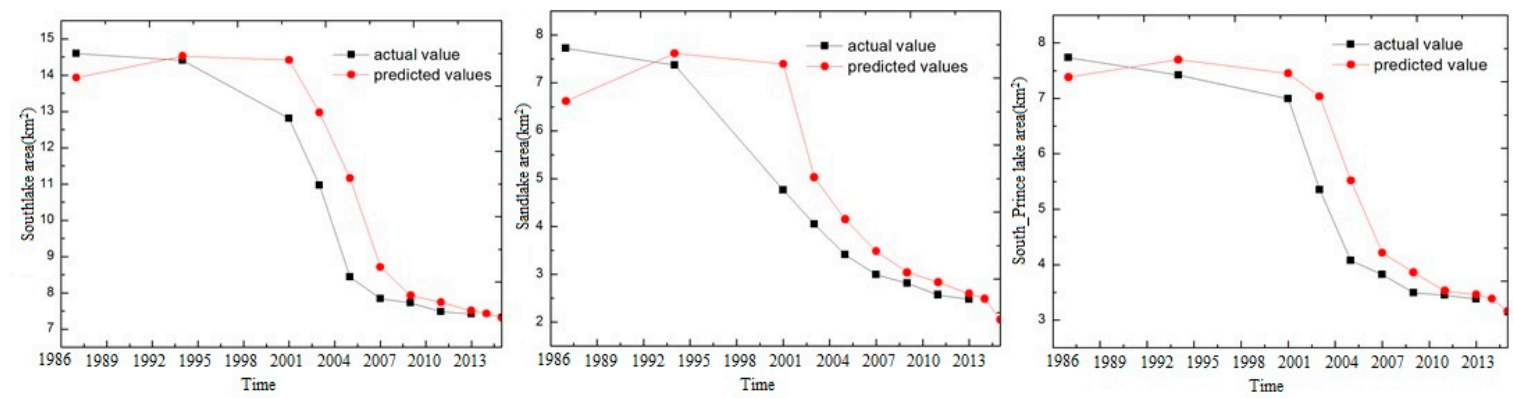

Figure 11. Areal changes of South Lake, Sand Lake, and South Prince Lake (1987-2013) and their predicted values (2014-2015). The areas of the lakes all decreased with increasing time, and the fitted values were closer to the actual values, indicating that the predicted values of more recent phases will be more accurate.

By applying Formulas (8) and (9), the $M A E$ and relative error of these three forecast models are 0.75 and 0.13 , respectively. In consideration that the lake areas are usually relatively large, the prediction accuracy of the test model is acceptable. Therefore, the modeling results prove that the exponential smoothing model is suitable for the short-term forecasting of lake area changes. As mentioned earlier, our group collected area data for 82 lakes for the period 1987-2013; consequently, we can obtain predictions of the area of each lake for 2015 by applying the exponential smoothing model, the results of which are compiled in Table 2, and we have completed field measurement work of all lakes area in 2015. 
Table 2. Lake area prediction results in the Wuhan urban area.

\begin{tabular}{|c|c|c|c|c|c|}
\hline Lake No. & $2015\left(\mathrm{~km}^{2}\right)$ & Predicted & Lake No. & $2015\left(\mathrm{~km}^{2}\right)$ & Predicted \\
\hline 1 & 0.155 & 0.135 & 42 & 0.132 & 0.024 \\
\hline 2 & 0.381 & 0.316 & 43 & 0.296 & 0.243 \\
\hline 3 & 3.340 & 2.940 & 44 & 0.723 & 0.654 \\
\hline 4 & 3.356 & 3.165 & 45 & 1.900 & 1.842 \\
\hline 5 & 1.266 & 1.013 & 46 & 1.594 & 1.443 \\
\hline 6 & 0.238 & 0.222 & 47 & 0.101 & 0.081 \\
\hline 7 & 0.105 & 0.096 & 48 & 0.978 & 0.799 \\
\hline 8 & 1.537 & 1.511 & 49 & 5.753 & 5.641 \\
\hline 9 & 1.168 & 1.064 & 50 & 0.701 & 0.642 \\
\hline 10 & 0.605 & 0.554 & 51 & 0.250 & 0.224 \\
\hline 11 & 0.191 & 0.177 & 52 & 3.479 & 3.074 \\
\hline 12 & 17.020 & 16.913 & 53 & 0.960 & 0.938 \\
\hline 13 & 0.576 & 0.549 & 54 & 0.897 & 0.756 \\
\hline 14 & 0.283 & 0.199 & 55 & 0.436 & 0.396 \\
\hline 15 & 0.280 & 0.267 & 56 & 0.424 & 0.411 \\
\hline 16 & 0.070 & 0.059 & 57 & 29.520 & 28.461 \\
\hline 17 & 0.074 & 0.064 & 58 & 1.146 & 1.078 \\
\hline 18 & 0.090 & 0.073 & 59 & 2.819 & 2.433 \\
\hline 19 & 30.586 & 29.462 & 60 & 0.684 & 0.465 \\
\hline 20 & 11.668 & 10.446 & 61 & 0.043 & 0.035 \\
\hline 21 & 0.110 & 0.076 & 62 & 0.033 & 0.025 \\
\hline 22 & 2.479 & 2.046 & 63 & 7.714 & 7.456 \\
\hline 23 & 0.314 & 0.233 & 64 & 0.570 & 0.421 \\
\hline 24 & 5.538 & 5.113 & 65 & 2.801 & 2.465 \\
\hline 25 & 0.087 & 0.084 & 66 & 0.241 & 0.213 \\
\hline 26 & 2.071 & 1.997 & 67 & 1.126 & 1.018 \\
\hline 27 & 7.419 & 6.944 & 68 & 1.679 & 1.412 \\
\hline 28 & 3.378 & 3.294 & 69 & 14.874 & 14.657 \\
\hline 29 & 0.318 & 0.279 & 70 & 2.108 & 2.011 \\
\hline 30 & 6.789 & 6.513 & 71 & 0.934 & 0.796 \\
\hline 31 & 0.203 & 0.179 & 72 & 0.800 & 0.649 \\
\hline 32 & 0.233 & 0.193 & 73 & 3.880 & 3.155 \\
\hline 33 & 0.334 & 0.244 & 74 & 11.187 & 10.842 \\
\hline 34 & 0.556 & 0.397 & 75 & 27.531 & 27.166 \\
\hline 35 & 0.073 & 0.071 & 76 & 42.780 & 40.499 \\
\hline 36 & 9.457 & 9.046 & 77 & 3.262 & 3.154 \\
\hline 37 & 0.202 & 0.183 & 78 & 28.586 & 26.744 \\
\hline 38 & 2.072 & 1.974 & 79 & 2.497 & 2.018 \\
\hline 39 & 1.773 & 1.465 & 80 & 0.029 & 0.027 \\
\hline 40 & 2.088 & 1.974 & 81 & 1.550 & 1.510 \\
\hline 41 & 0.206 & 0.188 & 82 & 8.594 & 8.211 \\
\hline
\end{tabular}

Table 2 shows that the average error was 0.23 and that the correlation coefficient between the two data sets was 0.98 . This indicates that the fitted data and the actual values have a high correlation, and therefore, the model forecasting ability is reliable. The largest predicted error was $2.281 \mathrm{~km}^{2}$ for lake 76, while lake 35 provided the smallest error of $0.002 \mathrm{~km}^{2}$. From Table 2, we can also conclude that the model predicted a lake area reduction of $18.494 \mathrm{~km}^{2}$ in 2015 . The average error reached 0.23 with a correlation coefficient of 0.98 , indicating that the model is reliable.

The modeling results also show that in the next two years of 2013, the lake area in the Wuhan urban district will continue to slowly shrink, but the rate of decrease will have obviously slowed down relative to the previous ten years. The ambition of current lake conservation measures is to stop the shrinkage of the lakes by enhancing their supervision and enforcing current construction policies created by the governmental departments. However, many more incentives to protect the lakes should be introduced. 


\subsection{Lake Change Mapping}

The predicted model can only reflect quantifiable changes in the lake areas. Therefore, to qualify the lake area changes, we rasterized the shapes of the lakes over every two years and applied a change detection algorithm within ENVI using a classification method to obtain three different categories: lake increase, lake decrease and no change. Finally, all of the layers were imported into ArcGIS, and we generated a lake change mapping (Figure 12).

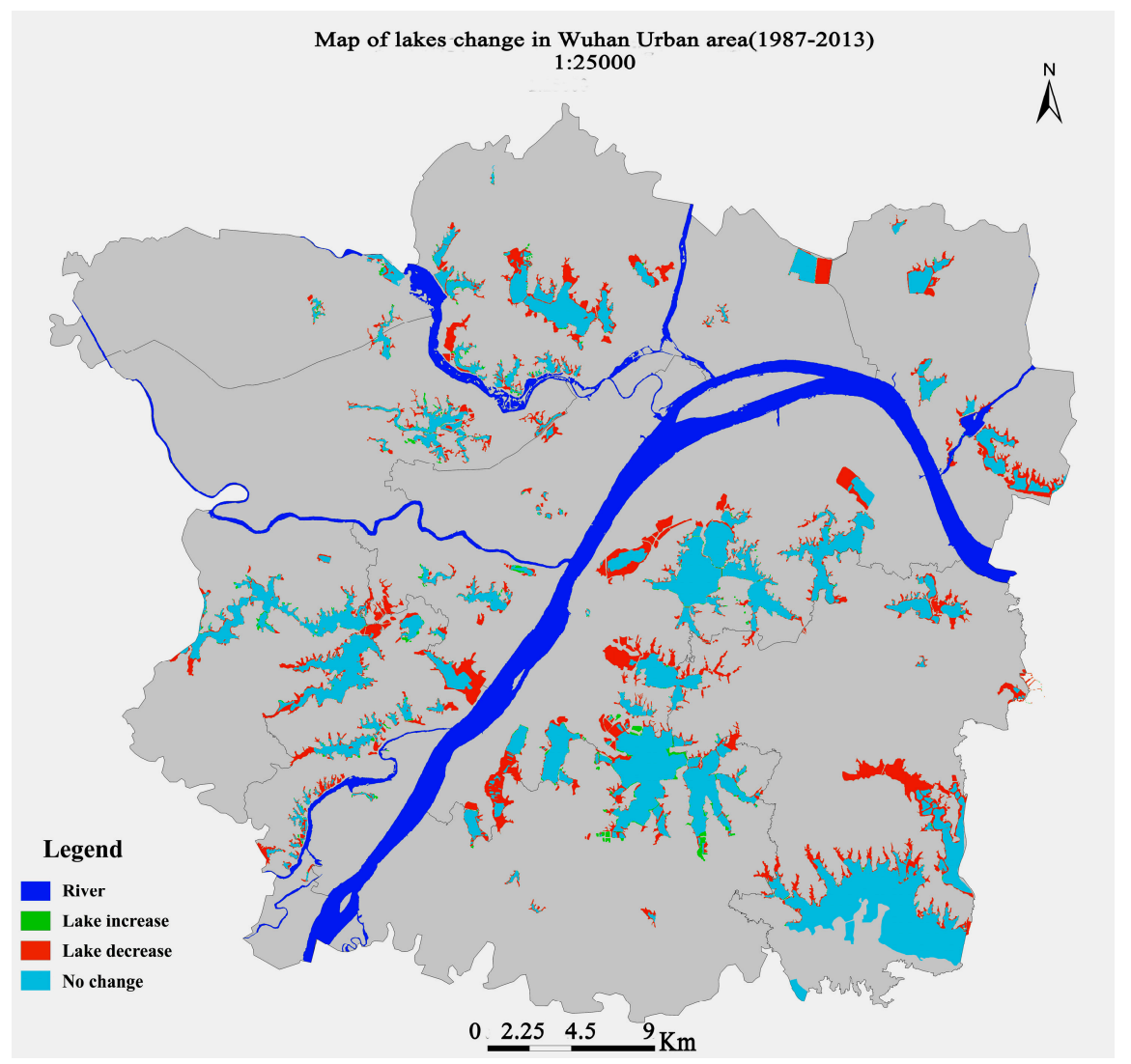

Figure 12. Map of lake area changes in the Wuhan urban area.

From the relative spatial distribution of the mapped lake changes, many shrinking lakes appeared in nearly every partition of the Wuhan development district, which indicates that an overall atrophy of the lakes was a common phenomenon throughout the research area. Through an investigation of the history of Wuhan development in recent years, the regions showing larger lake reductions were located in areas with continuous urban engineering construction and rapid population growth, and thus, there was a heavy influence of human activity on those lakes, and the transformations of the lake ecological environments were tremendous.

We can conclude from the mapping and statistical results that the total lake area within the urban development zone tended to decrease in 1987-2013. These changes took place within three stages: the lake area shrank gradually during 1987-2001, reduced more quickly during 2001-2005, and gradually decreased again during 2005-2015. According to relevant government historical data for 1987-2001, the primary reason for the reduction in the lake area was the transformation of many lakes into ponds to acquire arable land [42]. Meanwhile, the lake area shrank more quickly in 2001-2005 as a consequence of the speed of urbanization, which led to more land for construction, and parts of the lake areas were filled. Finally, in 2005-2015, the shrinkage gradually decreased because the Wuhan government strengthened the legislation for protecting the lake environments; consequently, the ecological health and stability of the major lakes have recovered. 


\section{Conclusions}

Our model was suitable for the prediction of water body variations, which could provide intuitive references for further environmental protection and management practices for lakes in the Wuhan area. Based on a long-term series of remote sensing imagery in conjunction with field survey data in the Wuhan urban area, we conducted a comprehensive analysis of the developmental trends of the Wuhan urban area and some key lakes. Then, we produced an easily understandable map of the extent of lake area changes for Wuhan that is suitable for use at local scales. Only a few important scenic spots exhibited significant growth or did not change (e.g., East Lake), our results showed that the environment and ecology were maintained in a relatively steady state; but in the urban of the Wuhan development area, big lakes (e.g., South Prince Lake) faced a danger of shrinking every year, because many real estate projects had been carried on around lakes, and some parts were filled directly for industrial use or fish farming; because of the excretion of water movement, we also found a more evident atrophy and shrinkage of the lakes in closer proximity to the coast of the Yangtze River (e.g., Sand Lake). Through an investigation of the history of Wuhan development in recent years, the regions showing larger lake reductions were located in areas with continuous urban engineering construction and rapid population growth, and thus, there was a heavy influence of human activity on those lakes, and the transformations of the lake ecological environments were tremendous.

Furthermore, this research forecasted the areal changes in the lake surfaces by applying an exponential smoothing method. Regarding additional data sources for further research, further research will carry more comprehensive investigation and meaningful models on environmental and ecological changes in lakes around Wuhan. Because other external factors that affect the shrinkage of lakes must be observed and recorded so we can obtain a more robust and accurate model.

Acknowledgments: This research was funded by the National High-Tech Research and Development Program of China (2012AA121303), and by the Engineering Research Center of Geospatial Information and Digital Technology (SIDT20170201), NASG. We are also grateful to the help of Wuhan surveying and mapping institute.

Author Contributions: G.H.D. and R.Q.N. conceived the experiments; G.H.D. developed the model code and processed the data and developed the graphics with assistance from R.Q.N.

Conflicts of Interest: The authors declare no conflict of interest.

\section{References}

1. Zha, Y.; Gao, J.; Ni, S. Use of normalized difference built-up index in automatically mapping urban areas from TM imagery. Int. J. Remote Sens. 2003, 24, 583-594. [CrossRef]

2. Zhu, Z.; Wang, S.; Woodcock, C.E. Improvement and expansion of the Fmask algorithm: Cloud, cloud shadow, and snow detection for Landsats 4-7, 8, and Sentinel 2 images. Remote Sens. Environ. 2015, 159, 269-277. [CrossRef]

3. Jackson, L.E. The relationship of urban design to human health and condition. Landsc. Urban Plan. 2003, 64, 191-200. [CrossRef]

4. Ehrenfeld, J.G. Evaluating wetlands within an urban context. Ecol. Eng. 2000, 15, 253-265. [CrossRef]

5. Feyisa, G.L.; Meilby, H.; Fensholt, R.; Proud, S.R. Automated Water Extraction Index: A new technique for surface water mapping using Landsat imagery. Remote Sens. Environ. 2014, 140, 23-35. [CrossRef]

6. Tulbure, M.G.; Broich, M.; Stehman, S.V.; Kommareddy, A. Surface water extent dynamics from three decades of seasonally continuous Landsat time series at subcontinental scale in a semi-arid region. Remote Sens. Environ. 2016, 178, 142-157. [CrossRef]

7. Bai, S.B.; Wang, J.; Zhou, P.-G.; Hou, S.S.; Lü, G.-N.; Xu, S.N. GIS-based logistic regression for landslide susceptibility mapping of the zhongxian segment in the Three Gorges area, China. Geomorphology 2010, 115, 23-31. [CrossRef]

8. Fourniadis, I.G.; Liu, J.G.; Mason, P.J. Landslide hazard assessment in the Three Gorges area, China, using ASTER imagery: Wushan-Badong. Geomorphology 2007, 84, 126-144. [CrossRef] 
9. Turcotte, R.; Fortin, J.P.; Rousseau, A.N.; Massicotte, S.; Villeneuve, J.P. Determination of the drainage structure of a watershed using a digital elevation model and a digital river and lake network. J. Hydrol. 2001, 240, 225-242. [CrossRef]

10. Mueller, N.; Lewis, A.; Roberts, D.; Ring, S.; Melrose, R.; Sixsmith, J.; Lymburner, L.; McIntyre, A.; Tan, P.; Curnow, S.; et al. Water observations from space: Mapping surface water from 25 years of Landsat imagery across Australia. Remote Sens. Environ. 2016, 174, 341-352. [CrossRef]

11. $\mathrm{Xu}, \mathrm{H} . \mathrm{Q}$. Modification of normalised difference water index (NDWI) to enhance open water features in remotely sensed imagery. Int. J. Remote Sens. 2006, 27, 3025-3033. [CrossRef]

12. Fisher, A.; Flood, N.; Danaher, T. Comparing Landsat water index methods for automated water classification in eastern Australia. Remote Sens. Environ. 2016, 175, 167-182. [CrossRef]

13. Mcfeeters, S.K. The use of Normalized Difference Water Index (NDWI) in the delineation of open water features. Int. J. Remote Sens. 1996, 17, 1425-1432. [CrossRef]

14. $\mathrm{Xu}, \mathrm{H} . \mathrm{Q}$. Dynamic monitoring of land-use/land-cover change and urban expansion in Shenzhen using Landsat imagery from 1988 to 2015. Int. J. Remote Sens. 2006, 38, 5388-5407.

15. Wilson, E.H.; Sader, S.A. Detection of forest harvest type using multiple dates of Landsat TM imagery. Remote Sens. Environ. 2002, 80, 385-396. [CrossRef]

16. Eldhuset, K. Combination of stereo SAR and InSAR for DEM generation using TanDEM-X spotlight data. Int. J. Remote Sens. 2017, 38, 4362-4378. [CrossRef]

17. Chibani, Y.; Houacine, A. The Joint use of HIS Transform and redundant wavelet decomposition for fusing multispectral and panchromatic images. Int. J. Remote Sens. 2002, 23, 3821-3833. [CrossRef]

18. FujitK, A.; Suzuki, R.; Nuimura, T.; Sakai, A. Performance of ASTER and SRTM DEMs, and their potential for assessing glacial lakes in the Lunana region, Bhutan Himalaya. J. Glaciol. 2008, 54, 220-228. [CrossRef]

19. Kiema, J.B.K. Texture analysis and data fusion in the extraction of topographic objects from satellite imagery. Int. J. Remote Sens. 2002, 23, 767-776. [CrossRef]

20. Rundquist, D.C.; Lawson, M.P.; Queen, L.P.; Cerveny, R.S. The relationship between summer-season rainfall events and lake-surface Area. Water Resour. Bull. 1987, 23, 493-508. [CrossRef]

21. Gill, T.; Johansen, K.; Phinn, S.; Trevithick, R.; Scarth, P.; Armston, J. A method for mapping Australian woody vegetation cover by linking continental-scale field data and long-term Landsat time series. Int. J. Remote Sens. 2017, 38, 679-705. [CrossRef]

22. Du, Z.Q.; Li, W.B.; Zhou, D.B.; Tian, L.Q.; Ling, F.; Wang, H.L.; Gui, Y.M.; Sun, B.Y. Analysis of Landsat-8 OLI imagery for land surface water mapping. Remote Sens. Lett. 2014, 5, 672-681. [CrossRef]

23. Ouma, Y.O.; Tateishi, R. A water index for rapid mapping of shore line changes of five east African rift valley lakes: An empirical analysis using Landsat TM and ETM + data. Int. J. Remote Sens. 2006, 27, 3153-3181. [CrossRef]

24. Lacoste, C.; Descombes, X.; Zerubia, J. Unsupervised line network extraction in remote sensing using a polyline process. Pattern Recognit. 2010, 43, 1631-1641. [CrossRef]

25. Zitov, B.; Flusser, J. Image registration methods: A survey. Image Vis. Comput. 2003, 21, 977-1000. [CrossRef]

26. Pozzi, F.; Matteo, T.D.; Aste, T. Exponential smoothing weighted correlations. Eur. Phys. J. B 2012, 85, 175. [CrossRef]

27. Monfared, M.A.S.; Ghandali, R.; Esmaeili, M. A new adaptive exponential smoothing method for non-stationary time series with level shifts. J. Ind. Eng. Int. 2014, 10, 209-216. [CrossRef]

28. Pee, E.Y.; Royset, J.O. On solving large-scale finite minimax problems using exponential smoothing. J. Optim. Theory Appl. 2011, 148, 390-421. [CrossRef]

29. Zhou, S.; Cui, J.; Ye, F.; Liu, H.; Zhu, Q. New smoothing SVM algorithm with tight error bound and efficient reduced techniques. Comput. Optim. Appl. 2013, 56, 599-617. [CrossRef]

30. Tangxun Lake, the Largest Lake in Wuhan City, Completed the Rectification of the Area Occupation. Available online: http:/ / news.xinhuanet.com/2017-08/06/c_1121439067.htm (accessed on 6 August 2017).

31. Roy, D.P.; Wulder, M.; Loveland, T.; Woodcock, C.; Allen, R.; Anderson, M.; Helder, D.; Irons, J.; Johnson, D.; Kennedy, R.; et al. Landsat-8: Science and product vision for terrestrial global change research. Remote Sens. Environ. 2014, 145, 154-172. [CrossRef]

32. Lu, D.; Weng, Q.A. Survey of image classification methods and techniques for improving classification performance. Int. J. Remote Sens. 2007, 28, 823-870. [CrossRef] 
33. Gao, B.C. NDWI-A normalized difference water index for remote sensing of vegetation liquid water from space. Remote Sens. Environ. 1996, 58, 257-266. [CrossRef]

34. Taylor, J.W. Exponential smoothing with a damped multiplicative trend. Int. J. Forecast. 2003, 19, 715-725. [CrossRef]

35. Corberan-Vallet, A.; Bermudez, J.D.; Vercher, E. Forecasting correlated time series with exponential smoothing models. Int. J. Forecast. 2011, 27, 252-265. [CrossRef]

36. Gardner, E.S., Jr.; Mckenzie, E. Note-Seasonal exponential smoothing with damped trends. Manag. Sci. 1989, 35, 372-376. [CrossRef]

37. Olaofe, Z.O. Wind energy predictions of small-scale turbine output using exponential smoothing and feed-forward neural network. Int. J. Energy Eng. 2015, 5, 28-42. [CrossRef]

38. Spelta, C.; Previdi, F.; Savaresi, S.M.; Bolzern, P.; Cutini, M.; Bisaglia, C.; Bertinotti, S.A. Performance analysis of semi-active suspensions with control of variable damping and stiffness. Veh. Syst. Dyn. 2011, 49, 237-256. [CrossRef]

39. Hyndman, R.J.; Koehler, A.B.; Snyder, R.D.; Grose, S. A state space framework for automatic forecasting using exponential smoothing methods. Int. J. Forecast. 2002, 18, 439-454. [CrossRef]

40. Hyndman, R.J.; Khandakar, Y. Automatic Time Series Forecasting: The forecast Package for R. J. Stat. Softw. 2008, 27, 1-22. [CrossRef]

41. Dong, Z.; Yang, D.; Reindl, T.; Walsh, W.M. Short-term solar irradiance forecasting using exponential smoothing state space model. Energy 2013, 55, 1104-1113. [CrossRef]

42. Compiling committee of Hubei water resources development history. In Hubei Water Resources Development History; China Water Power Press: Beijing, China, 2000; pp. 254-256. (In Chinese)

(C) 2018 by the authors. Licensee MDPI, Basel, Switzerland. This article is an open access article distributed under the terms and conditions of the Creative Commons Attribution (CC BY) license (http://creativecommons.org/licenses/by/4.0/). 